\title{
Therapeutic manipulation of peroxynitrite attenuates the development of opiate-induced antinociceptive tolerance in mice
}

\author{
Carolina Muscoli, 1,2 Salvatore Cuzzocrea, ${ }^{3,4}$ Michael M. Ndengele, 5 \\ Vincenzo Mollace, ${ }^{1,6}$ Frank Porreca, ${ }^{7}$ Francesca Fabrizi, ${ }^{8}$ Emanuela Esposito, ${ }^{4}$ \\ Emanuela Masini, ${ }^{8}$ George M. Matuschak, ${ }^{5}$ and Daniela Salvemini ${ }^{5}$ \\ ${ }^{1}$ Faculty of Pharmacy, University of Catanzaro "Magna Graecia," Roccelletta di Borgia, Catanzaro, Italy. ${ }^{2}$ Centro di Neurofarmacologia Sperimentale, \\ IRCCS Mondino-Università Tor Vergata di Roma, Rome, Italy. ${ }^{3}$ Department of Clinical and Experimental Medicine and Pharmacology, \\ School of Medicine, University of Messina, Messina, Italy. " \\ ${ }^{5}$ Department of Internal Medicine, Division of Pulmonary, Critical Care and Sleep Medicine, Saint Louis University School of Medicine, \\ St. Louis, Missouri, USA. ${ }^{6}$ IRCCS San Raffaele Pisana, Rome, Italy. 'Department of Pharmacology, University of Arizona, Tucson, Arizona, USA. \\ ${ }^{8}$ Department of Preclinical and Clinical Pharmacology, University of Florence, Florence, Italy.
}

\begin{abstract}
Severe pain syndromes reduce quality of life in patients with inflammatory and neoplastic diseases, often because chronic opiate therapy results in reduced analgesic effectiveness, or tolerance, leading to escalating doses and distressing side effects. The mechanisms leading to tolerance are poorly understood. Our studies revealed that development of antinociceptive tolerance to repeated doses of morphine in mice was consistently associated with the appearance of several tyrosine-nitrated proteins in the dorsal horn of the spinal cord, including the mitochondrial isoform of superoxide $\left(\mathrm{O}_{2}^{-}\right)$dismutase, the glutamate transporter GLT-1, and the enzyme glutamine synthase. Furthermore, antinociceptive tolerance was associated with increased formation of several proinflammatory cytokines, oxidative DNA damage, and activation of the nuclear factor poly(ADPribose) polymerase. Inhibition of $\mathrm{NO}$ synthesis or removal of $\mathrm{O}_{2}^{-}$blocked these biochemical changes and inhibited the development of tolerance, pointing to peroxynitrite $\left(\mathrm{ONOO}^{-}\right)$, the product of the interaction between $\mathrm{O}_{2}{ }^{-}$and $\mathrm{NO}$, as a signaling mediator in this setting. Indeed, coadministration of morphine with the $\mathrm{ONOO}^{-}$decomposition catalyst, $\mathrm{Fe}$ (III) $5,10,15,20$-tetrakis( $N$-methylpyridinium-4-yl)porphyrin, blocked protein nitration, attenuated the observed biochemical changes, and prevented the development of tolerance in a dose-dependent manner. Collectively, these data suggest a causal role for $\mathrm{ONOO}^{-}$in pathways culminating in antinociceptive tolerance to opiates. Peroxynitrite $\left(\mathrm{ONOO}^{-}\right)$decomposition catalysts may have therapeutic potential as adjuncts to opiates in relieving suffering from chronic pain.
\end{abstract}

\section{Introduction}

Chronic, severe pain is a significant health problem (1). One third of Americans suffer from some form of chronic pain, and in over $30 \%$ it is resistant to analgesic therapy (1). The economic impact of pain is equally large, at approximately $\$ 100$ billion annually (1). Opiate/narcotic analgesics, typified by morphine sulfate, are the most effective treatments for acute and chronic severe pain, but their clinical utility is often hampered by the development of analgesic tolerance as well as by de novo painful hypersensitivity to innocuous and noxious stimuli, phenomena observed in both animal and human studies (2-4). With respect to morphine in particular, tolerance necessitates escalating doses to achieve equivalent pain relief (5), even as morphine-induced hypersensitivity subverts the therapeutic impact of such dose increases (2-4). This complex pathophysiological cycle contributes to decreased quality of life in the growing population of subjects with chronic pain because

Nonstandard abbreviations used: CuZnSOD, cytosolic SOD; FeTM-4-PyP ${ }^{5+}$, Fe(III) 5,10,15,20-tetrakis( $N$-methylpyridinium-4-yl)porphyrin; GS, glutamine synthase; GT, glutamate transporter; L-NAME, N-nitro-L-arginine methyl ester; MnSOD, manganese $\mathrm{O}_{2}{ }^{-}$dismutase; $\mathrm{MnTBAP}^{3-}, \mathrm{Mn}(\mathrm{III})$ 5,10,15,20-tetrakis(4-carboxylatophenyl)porphyrin; $\mathrm{NMDAR}, \mathrm{NMDA}$ receptor; $\mathrm{O}_{2}^{-}$, superoxide; $\mathrm{ONOO}^{-}$, peroxynitrite; PARP, poly(ADP-ribose) polymerase; $\mathrm{SOD}, \mathrm{O}_{2}^{-}$dismutase.

Conflict of interest: The authors have declared that no conflict of interest exists. Citation for this article: J. Clin. Invest. 117:3530-3539 (2007). doi:10.1172/JCI32420. of oversedation, reduced physical activity, respiratory depression, constipation, potential for addiction, and other side effects (5). Accordingly, there is great interest in new approaches to maintain opiate efficacy during repetitive dosing for chronic pain, without engendering tolerance or unacceptable side effects.

The mechanisms by which prolonged opiate exposure induces tolerance and hypersensitivity remain unclear, although a role for neuronal apoptosis $(6,7)$ and neuroimmune activation, which include glial cell activation and release of proinflammatory cytokines such as TNF- $\alpha$, IL-1 $\beta$, and IL- 6 at the level of the spinal cord, have all been demonstrated (8-10). $\mathrm{ONOO}^{-}$, the product of the interaction between superoxide $\left(\mathrm{O}_{2}^{-}\right)$and $\mathrm{NO}$, is a potent proinflammatory and proapoptotic reactive species (11-13) recently implicated in the development of thermal hyperalgesia (defined as augmented pain intensity in response to painful stimuli) associated with inflammation and in response to spinal activation of the NMDA receptor (NMDAR) $(14,15)$. Other biologically relevant features of $\mathrm{ONOO}^{-}$include posttranslational tyrosine nitration and consequent modification of protein function (16) as exemplified by mitochondrial manganese $\mathrm{O}_{2}{ }^{-}$dismutase (MnSOD), the enzyme that normally keeps concentrations of $\mathrm{O}_{2}{ }^{-}$dismutase (SOD) under tight control (17). ONOO--mediated nitration of MnSOD inactivates the enzyme, leading to an increase in $\mathrm{O}_{2}^{-}$levels (18-22), an event favoring increased $\mathrm{ONOO}^{-}$formation, which 
A

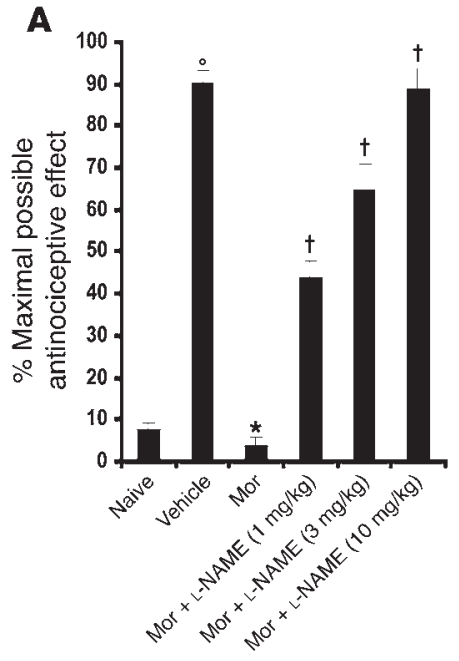

B

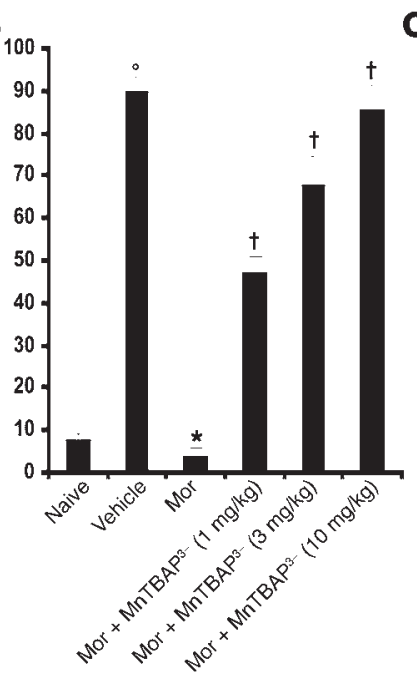

C

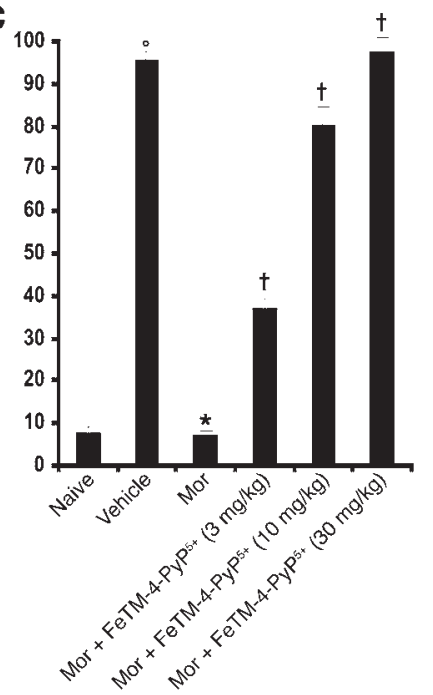

Figure 1

On day 5 acute injection of morphine $(3 \mathrm{mg} / \mathrm{kg}$ ) in animals that received saline over 4 days (vehicle group) produced a significant antinociceptive response when compared with responses observed in animals that received an equivalent volume of saline (naive group). On the other hand, a significant loss to the antinociceptive effect of the acute injection of morphine was observed in animals that received repeated administration of morphine over 4 days (morphine group; Mor). Coadministration of morphine over 4 days with (A) L-NAME (1-10 mg/kg/d), (B) MnTBAP3- (1-10 mg/kg/d), or (C) FeTM-4-PyP ${ }^{+}(3-30 \mathrm{mg} / \mathrm{kg} / \mathrm{d})$ inhibited the development of tolerance in a dose-dependent manner. Results are expressed as mean \pm SEM for 12 animals. ${ }^{\circ} P<0.001$ for vehicle versus naive; ${ }^{*} P<0.001$ for morphine versus vehicle; ${ }^{\dagger} P<0.001$ for morphine plus drug versus morphine alone.

in turn contributes to the development of hyperalgesia associated with acute inflammation and occurs in response to NMDA receptor activation $(14,15)$. The role(s) and significance of posttranslational nitration in opiate tolerance are currently unknown. Scientific knowledge gathered from research in fields other than opiate tolerance or pain, especially amyotrophic lateral sclerosis (ALS) and septic shock revealed that $\mathrm{ONOO}^{-}$nitrates and inactivates the transport activity of glutamate transporters (GTs) and the enzymatic activity of glutamine synthase (GS), proteins of central importance in glutamate homeostasis (23-25). Glutamate neurotransmission, in particular that mediated via the NMDAR, is involved in the development of opiate tolerance (26). Glutamate, a primary endogenous ligand for the NMDAR, is not metabolized by extracellular enzymes, but rather has to be removed from the synaptic cleft (27). The homeostasis of extracellular glutamate is tightly regulated by sodium-dependent high-affinity GTs in the plasma membranes of both neurons and glial cells, which are responsible for more than $80 \%$ of total glutamate transport (27). As such, these transporters prevent overstimulation of glutamate receptors and excitotoxicity (24), whereas loss of the transport function of these proteins leads to increased glutamate levels in the synaptic cleft, overstimulation of NMDAR, and neurotoxicity $(28,29)$. In contradistinction to the key role of GTs in regulating the homeostasis of extracellular glutamate, GS plays a pivotal role in its intracellular metabolic fate. Glutamate uptake into glial cells is followed by its conversion into nontoxic glutamine by this enzyme; thus inactivation of GS has been linked to neurotoxicity (30). Although the role of posttranslational ONOO--induced nitration of GTs and GS in opiate tolerance has not to our knowledge been previously investigated, it is possible that compromise of optimal glutamatergic homeostasis by nitration can promote glutamate-mediated neurotoxicity that often accompanies antinociceptive tolerance $(31,32)$.
Collectively we show in this study that formation of $\mathrm{ONOO}^{-}$in the spinal cord plays a critical role in the development of morphine-induced antinociceptive tolerance through at least 3 biochemical pathways: (a) posttranslational nitration; (b) neuroimmune activation and release of proinflammatory cytokines; and (c) oxidative DNA damage and poly(ADP-ribose) polymerase (PARP) activation. Thus our studies provide a valid pharmacological basis for developing $\mathrm{ONOO}^{-}$decomposition catalysts as potent adjuncts to opiates in the management of chronic pain, addressing an issue of major clinical and socioeconomic importance while laying the basis for interventions with strong therapeutic potential.

\section{Results}

The development of morphine-induced tolerance is associated with protein tyrosine nitration and this is inbibited by $N^{G}$-nitro-L-arginine methyl ester and $M n T B A P^{3-}$. When compared with animals receiving an equivalent injection of saline (naive group), acute injection of morphine $(3 \mathrm{mg} / \mathrm{kg}$ ) in animals that received saline over 4 days (vehicle group) produced a significant near-maximal antinociceptive response (percentage of maximum possible antinociceptive effect, ranging from $90 \%$ to $95 \%$ ) (Figure 1). The antinociceptive effect of the acute dose of morphine was not associated with the appearance of tyrosine-nitrated proteins in the superficial layers of the dorsal horn as detected by immunohistochemistry (Figure 2). On the other hand, when compared with the antinociceptive response to acute morphine in the vehicle group, repeated administration of morphine over the same time course (morphine group) led to the development of antinociceptive tolerance as evidenced by a significant loss of its antinociceptive response (Figure 1). Baseline latencies in vehicle and morphine groups were statistically insignificant from each other and ranged between 6 and 8 seconds $(n=12)$. The development of tolerance was associated with the appearance of tyrosine-nitrated proteins in the superficial layers of the dorsal horn as detected by 
A $\quad x 4$

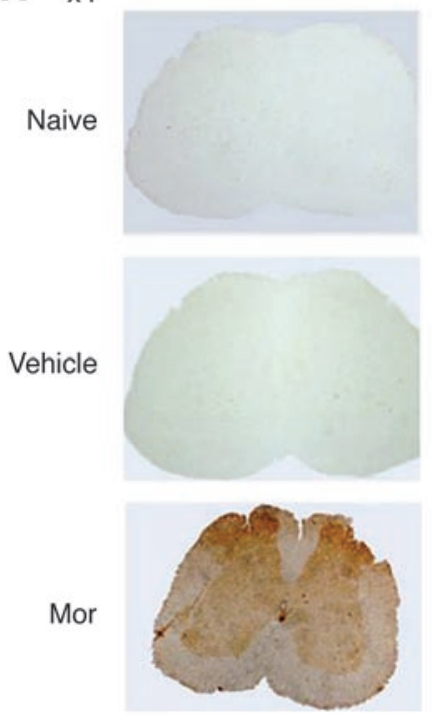

B $\times 10$

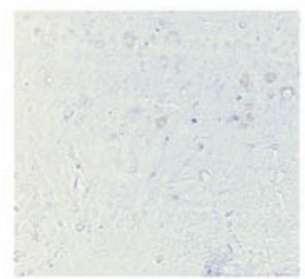

Naive

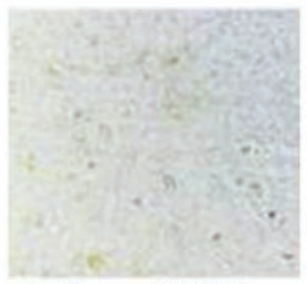

Mor + L-NAME

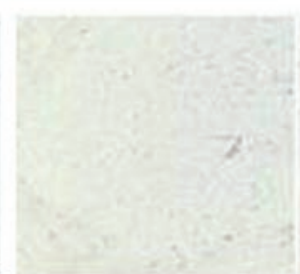

Vehicle

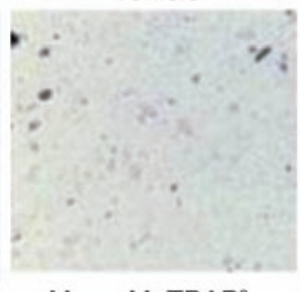

Mor + MnTBAP'-

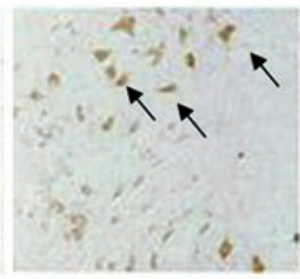

Mor

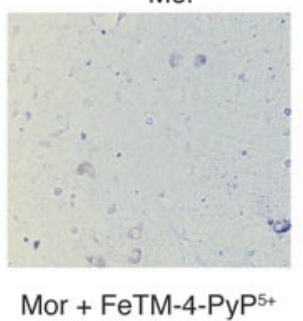

\section{Figure 2}

Micrographs of the superficial layers of the dorsal horn of the lumbar enlargement (L4-L6) of the spinal cord illustrating nitrotyrosine staining. (A) On day 5 acute injection of morphine $(3 \mathrm{mg} / \mathrm{kg})$ or its vehicle did not lead to the appearance of nitrotyrosine staining in the superficial layers of the dorsal horn. On the other hand, acute administration of morphine on day 5 after repeated administration of morphine led to significant protein nitration in the superficial layers of the dorsal horn with no staining in the ventral horn. Original magnification, $\times 4$. (B) Coadministration of morphine over 4 days with L-NAME (10 mg/kg/d), MnTBAP3- $(10 \mathrm{mg} / \mathrm{kg} / \mathrm{d})$, or FeTM-4-PyP5+ $(30 \mathrm{mg} / \mathrm{kg} / \mathrm{d})$ blocked nitrotyrosine formation. Original magnification, $\times 10$. Micrographs are representative of at least 3 from different animals in experiments performed on different days.

immunohistochemistry (Figure 2). No staining was observed in the ventral horn (Figure 2A). MnSOD but not cytosolic SOD (CuZnSOD; Figure 3, A and D), the GT GLT-1 (Figure 4A), and GS (Figure 4C) were proteins found to be nitrated in the dorsal horn as shown by immunoprecipitation. Representative gels obtained from 6 animals are shown in Figures 3 and 4; the composite ( $n=6$ animals) of the densitometry data resulting from these experiments is shown in Table 1. Posttranslational nitration of MnSOD (Figure 3A) led to functional enzymatic inactivation as evidenced by loss of its catalytic activity to dismute $\mathrm{O}_{2}{ }^{-}$as measured spectrophotometrically $(n=12)$ (Figure 3B). In contrast, the enzymatic activity of CuZnSOD was not affected $(n=12)$ (Figure $3 \mathrm{E})$. Coadministration of morphine with the nonselective NOS inhibitor N-nitro-L-arginine methyl ester (L-NAME; ref. 33) or with the nonselective $\mathrm{O}_{2}{ }^{-}$scavenging agent MnTBAP $^{3-}$ [Mn(III) 5,10,15,20-tetrakis(4-carboxylatophenyl) porphyrin); ref. 34, 35] inhibited in a dose-dependent manner $(1-10 \mathrm{mg} / \mathrm{kg} / \mathrm{d}, n=12)$ the development of antinociceptive tolerance (Figure 1). When tested alone at the highest dose, neither L-NAME nor $\mathrm{MnTBAP}^{3}$ (both at $10 \mathrm{mg} / \mathrm{kg} / \mathrm{d}$ ) had antinociceptive effects. Thus on day 5 hot plate latencies following a s.c. injection of saline in vehicle-treated animals or in animals that received L-NAME or MnTBAP $^{3}$ were statistically insignificant and ranged between 6 and 7 seconds ( $n=12$; data not shown). Inhibition of antinociceptive tolerance by L-NAME or $\mathrm{MnTBAP}^{3-}$ was associated with a reduction in nitrotyrosine staining in the superficial layers of the dorsal horn (Figure 2B); attenuation of posttranslational nitration of MnSOD (Figure 3A), GLT-1, and GS $(n=6)$ (Figure 3A and Figure 4, A and $\mathrm{C})$; and protection of the enzymatic inactivation of $\operatorname{MnSOD}(n=12)$ (Figure 3B). These results suggest that inhibition of tolerance by L-NAME or $\mathrm{MnTBAP}^{3-}$ is secondary, at least in part, to inhibition of posttranslational nitration of MnSOD, GLT-1, and GS.
The inhibitory effects of L-NAME or $\mathrm{MnTBAP}^{3-}$ were not attributable to acute antinociceptive interactions between L-NAME or $\mathrm{MnTBAP}^{3-}$ and acute morphine doses, since the response to acute morphine given at 3 different doses $(0.3-3 \mathrm{mg} / \mathrm{kg}, n=10)$ in animals treated with the highest dose of L-NAME or MnTBAP ${ }^{3-}$ $(10 \mathrm{mg} / \mathrm{kg} / \mathrm{d}, n=10)$ or their vehicle over 4 days was statistically insignificant (Figure 5).

The development of morphine-induced tolerance is associated with increased cytokine formation, oxidative DNA damage, and PARP activation and is inbibited by $L-N A M E$ and $M n T B A P^{3-}$. On day 5 when compared with the naive group, acute injection of morphine $(3 \mathrm{mg} / \mathrm{kg}, n=12)$ in vehicle-treated mice did not increase dorsal horn tissue levels of TNF- $\alpha$, IL- $1 \beta$, or IL- 6 as measured by ELISA using commercially available kits (Figure 6); did not increase levels of 8-OHdG, a marker of oxidative DNA damage (Figure 7A); and did not increase the activity of PARP measured as described previously (36) (Figure 7B). On the other hand, acute injection of morphine in mice in the morphine group led to a significant increase in TNF- $\alpha$, IL-1 $\beta$, and IL-6 $(n=12)$ (Figure 6); increased the levels of 8 -OHdG $(n=12)$; and increased PARP activity $(n=12)$ (Figure 7$)$ in dorsal horn tissues. This increase was attenuated by coadministration of morphine over 4 days with L-NAME or MnTBAP ${ }^{3-}$ (both at $10 \mathrm{mg} / \mathrm{kg} / \mathrm{d}, n=12$ ) (Figures 6 and 7).

$\mathrm{ONOO}^{-}$formed by $\mathrm{NO}$ and $\mathrm{O}_{2}^{-}$is a key mediator in the biochemical events leading to antinociceptive tolerance. Because $\mathrm{NO}$ is known to react with $\mathrm{O}_{2}^{-}$at a diffusion-limited rate to form $\mathrm{ONOO}^{-}(12)$, results obtained with L-NAME and $\mathrm{MnTBAP}^{3-}$ indirectly suggest that $\mathrm{ONOO}^{-}$from these reactive species is the common denominator in the molecular and biochemical pathways leading to antinociceptive tolerance. The important role of $\mathrm{ONOO}^{-}$in tolerance was confirmed by the use of a well-known and -characterized $\mathrm{ONOO}^{-}$decomposition catalyst, 
A

B
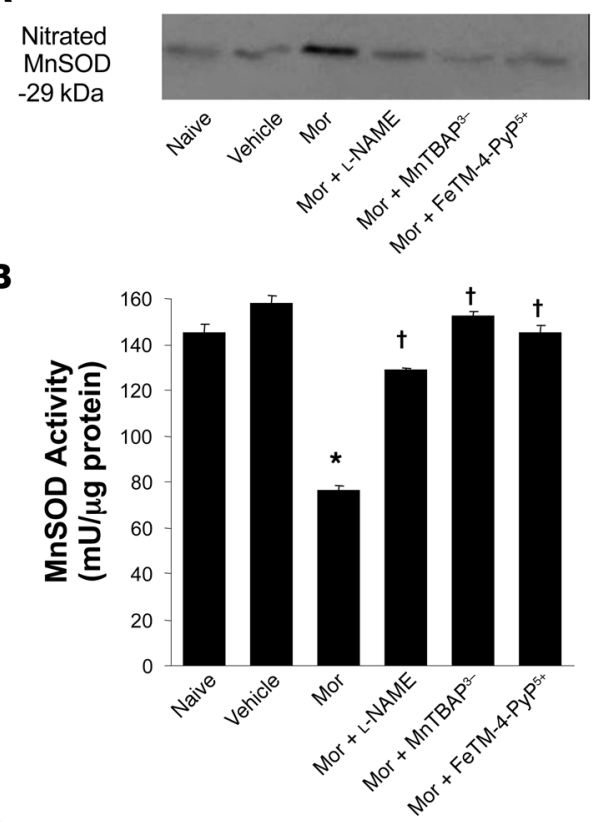

C

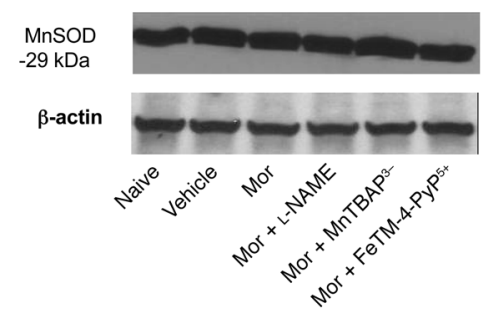

D

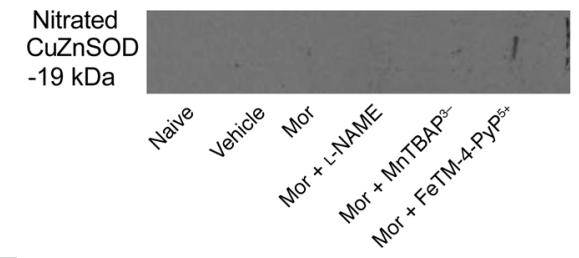

E

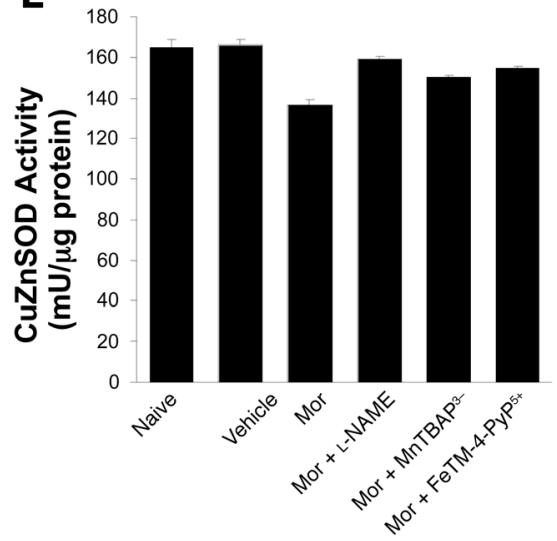

F

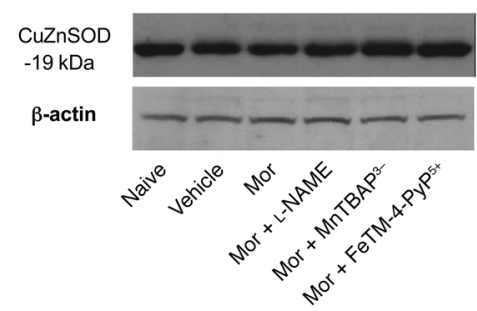

Figure 3

When compared with naive group, vehicle group did not lead to nitration of MnSOD or CuZnSOD in dorsal horn tissues as measured by immunoprecipitation. On the other hand, acute administration of morphine in animals that received repeated administration of morphine led to significant nitration of MnSOD (A) but not CuZnSOD (D). (A) Coadministration of morphine over 4 days with L-NAME $(10 \mathrm{mg} / \mathrm{kg} / \mathrm{d})$, MnTBAP $^{3-}(10 \mathrm{mg} / \mathrm{kg} / \mathrm{d})$, or FeTM-4-PyP ${ }^{5+}(30 \mathrm{mg} / \mathrm{kg} / \mathrm{d})$ prevented MnSOD nitration. (B) Posttranslational nitration of MnSOD led to functional enzymatic inactivation as evidenced by loss of its catalytic activity to dismute $\mathrm{O}_{2}{ }^{-}$as measured spectrophotometrically. Coadministration of morphine with L-NAME (10 mg/kg/d), MnTBAP ${ }^{-}$(10 mg/kg/d), or FeTM-4-PyP $5+(30 \mathrm{mg} / \mathrm{kg} / \mathrm{d})$ restored the enzymatic activity of MnSOD. (E) The enzymatic activity of CuZnSOD was not affected. When compared with the naive or vehicle group, repeated administration of morphine did not change the total amount of MnSOD (C) or CuZnSOD (F) in dorsal horn tissues as measured by Western blotting analysis. Gels shown in $\mathbf{A}, \mathbf{C}, \mathbf{D}$, and $\mathbf{F}$ are representative of gel results obtained from 6 animals. A composite $(n=6)$ of the densitometry data resulting from these experiments is shown in Table 1. ${ }^{*} P<0.001$ for morphine alone versus vehicle; ${ }^{\top} P<0.001$ for morphine plus drug versus morphine alone.

hyperalgesia, a phenomenon associated with inhibition of nitrotyrosine formation in paw tissues as well as release of tissue levels of TNF- $\alpha$, IL- $1 \beta$, and IL- 6 and attenuation of increased PARP activity (15, 37-39).

Theinhibitoryeffects of FeTM-4-PyP ${ }^{5+}$ were not attributable to acute antinociceptive interactions between FeTM-4-PyP ${ }^{5+}$ and morphine, since the response to acute morphine $(0.3-10 \mathrm{mg} / \mathrm{kg}, n=10)$ in animals treated with the highest dose of FeTM$4-\mathrm{PyP}^{5+}(30 \mathrm{mg} / \mathrm{kg} / \mathrm{d}, n=10)$ or its vehicle over 4 days was statistically insignificant (Figure 5). When tested alone at the highest dose, FeTM-4-PyP $\mathrm{P}^{5+}$ $(30 \mathrm{mg} / \mathrm{kg} / \mathrm{d})$ had no antinociceptive effect. Thus on day 5 hot plate latencies following a s.c. injection of saline in the vehicle group or in animals that received the highest dose of FeTM-4$\mathrm{Py}^{5+}$ were statistically insignificant and ranged between 6 and 7 seconds ( $n=12$; data not shown).

L-NAME, MnTBAP ${ }^{3-}$, and FeTM-4$P y P^{5+}$ do not reverse established morphine tolerance. Loss of the antinociceptive effect of morphine observed on day 5 in the morphine group was not restored by a single administration of LNAME, MnTBAP ${ }^{3-}$ (both at $10 \mathrm{mg} / \mathrm{kg}$, $n=10)$, or FeTM-4-PyP ${ }^{5+}(30 \mathrm{mg} / \mathrm{kg}$, $n=10)$ given by i.p. injection $15 \mathrm{~min}$ utes before the acute dose of morphine $(3 \mathrm{mg} / \mathrm{kg})$. Thus the percentage of maximum possible antinociceptive effect was $95 \pm 2,8 \pm 2,10 \pm 3,7 \pm 2$, and $11 \pm 2$ for the vehicle, morphine, morphine plus L-NAME, morphine plus $\mathrm{MnTBAP}^{3-}$, and morphine plus FeTM-4-PyP ${ }^{5+}$ groups, respectively $(n=10, P<0.5)$. These results suggest that these pharmacological agents inhibit the development, and not the expression, of tolerance.
FeTM-4-PyP ${ }^{5+}(\mathrm{Fe}[\mathrm{III}]$ 5,10,15,20-tetrakis[ $N$-methylpyridinium4-yl]porphyrin) (13). Indeed, coadministration of morphine with FeTM-4-PyP ${ }^{5+}$ inhibited the development of antinociceptive tolerance in a dose-dependent manner $(3-30 \mathrm{mg} / \mathrm{kg} / \mathrm{d}, n=12)$ (Figure 1$)$. In addition, FeTM-4-PyP ${ }^{5+}(30 \mathrm{mg} / \mathrm{kg} / \mathrm{d}, n=6)$ attenuated nitrotyrosine formation (Figure 2B); posttranslational nitration of MnSOD (Figure 3A), GLT-1 and GS (Figure 4, A and C); and restored the enzymatic activity of MnSOD $(n=12)$ (Figure 3B). Furthermore, FeTM-4-PyP ${ }^{5+}$ blocked in a dose-dependent manner $(3-30 \mathrm{mg} / \mathrm{kg} / \mathrm{d}, n=12)$ the increased formation of TNF- $\alpha$, IL-1 $\beta$, IL-6 (Figure 6), and 8-OHdG and prevented the increase in PARP activity (Figure 7) in dorsal horn tissues. These results are consistent with our previous findings showing that FeTM-4- $\mathrm{Py}^{5+}(13,37)$ blocks carrageenan-induced thermal

\section{Discussion}

Prolonged use of opiates results in antinociceptive tolerance, such that higher doses are required to achieve equivalent analgesia (5) or antinociception $(4,40,41)$. Adaptive modifications in cellular responsiveness and particularly desensitization and downregulation of opioid receptors are at the origin of this phenomenon (42). By contrast, an alternative hypothesis is that stimulation of opioid receptors over time triggers activation of antiopioid systems that in turn reduce sensory thresholds, thereby resulting in hypersensitivity to tactile stimulation (i.e., allodynia) and to noxious thermal stimulation (i.e., hyperalgesia) $(40,43,44)$. As a corollary to this hypothesis, such opioid-induced hypersensitivity paradoxically diminishes the net analgesic effect of the opioid agonist (40, 43, 


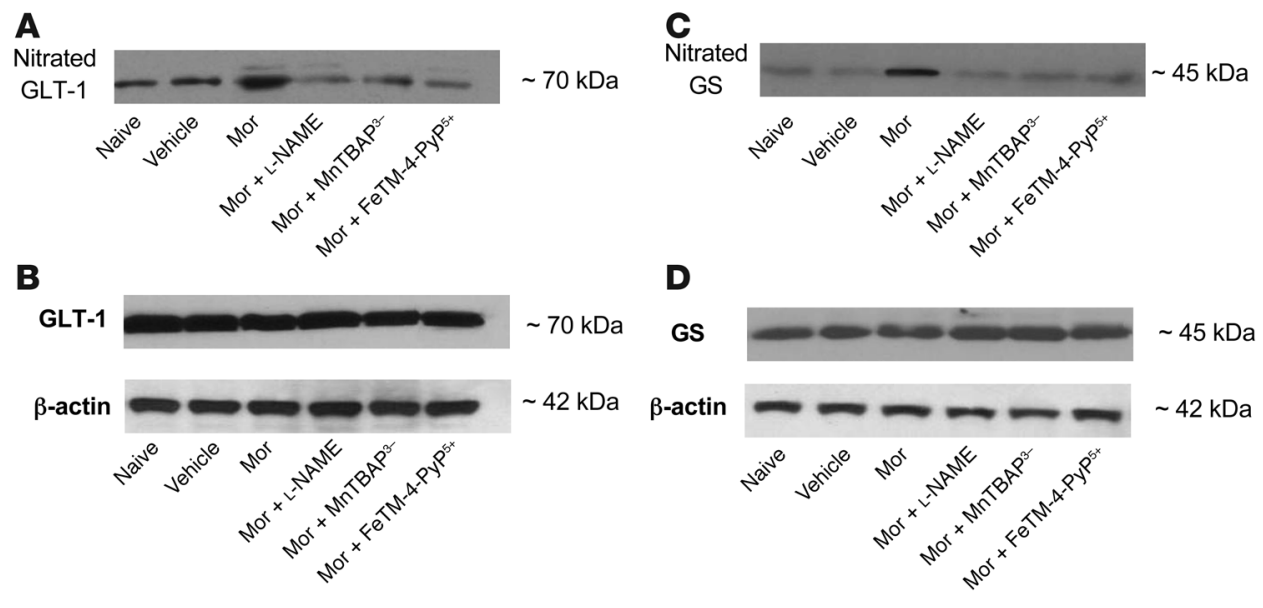

Figure 4

On day 5 the acute injection of morphine $(3 \mathrm{mg} / \mathrm{kg}$ ) (vehicle group) but not its vehicle (naive group) in animals that received saline over 4 days did not lead to nitration of the GT GLT-1 or GS in dorsal horn tissues as measured by immunoprecipitation. ( $\mathbf{A}$ and $\mathbf{C}$ ) On the other hand, acute administration of morphine in the morphine group led to significant nitration of GLT-1 (A) and GS (C). Coadministration of morphine over 4 days with L-NAME $(10 \mathrm{mg} / \mathrm{kg} / \mathrm{d})$, MnTBAP ${ }^{3-}(10 \mathrm{mg} / \mathrm{kg} / \mathrm{d})$, or FeTM-4-PyP5+ $(30 \mathrm{mg} / \mathrm{kg} / \mathrm{d})$ prevented the nitration of both GLT-1 and GS. (B and D) When compared with the naive or vehicle groups, repeated administration of morphine did not change the total amount of GLT-1 (B) or GS (D) in dorsal horn tissues as measured by Western blotting analysis. Gels are representative of gel results obtained from 6 animals. A composite $(n=6)$ of the densitometry data resulting from these experiments is shown in Table 1.

44). Support for this alternative hypothesis has been evidenced in vivo in animals $(2,45,46)$ and humans $(3,47,48)$. Thus it is thought that analgesic tolerance arises when pain facilitatory systems become sensitized or hyperactive after repeated opioid use. Our focus herein has been to address the involvement of ONOOin the maladaptive process of altered nociceptive signaling within the dorsal horn of the spinal cord, as it relates to the clinical problem of morphine-induced tolerance.

Results of our studies using indirect pharmacological approaches to inhibit the formation of $\mathrm{ONOO}^{-}$(L-NAME and MnTBAP'-) and a direct pharmacological approach to catalytically decompose $\mathrm{ONOO}^{-}\left(\mathrm{FeTM}^{-4}-\mathrm{PyP}^{5+}\right)$ reveal that $\mathrm{ONOO}^{-}$is a key signaling molecule in morphine-induced antinociceptive tolerance, contributing to its development via at least 3 biochemical pathways as summarized in Figure 8. A biologically relevant feature of the involvement of $\mathrm{ONOO}^{-}$and related species in pathophysiological conditions is posttranslational tyrosine nitration and consequent modification of protein function (16). Protein nitration is increasingly recognized as an important occurrence during cell signaling and regulation of protein activity (49). Several proteins are now known to be nitrated by $\mathrm{ONOO}^{-}$, with subsequent loss or gain of function associated with this modification (16). We have recently reported that nitration and enzymatic inactivation of mitochondrial MnSOD plays a key role in the development of hyperalgesia occurring during the development of inflammation (15) and in response to NMDA receptor activation (14). Here we show that nitration and subsequent enzymatic inactivation of its catalytic ability to dismute $\mathrm{O}_{2}{ }^{-}$contributes to the development of antinociceptive tolerance. Thus inhibition of MnSOD nitration and enzymatic inactivation by FeTM-4-PyP ${ }^{5+}$ (or L-NAME and $\mathrm{MnTBAP}^{3-}$ ) prevented the occurrence of tolerance, suggesting that mitochondrial activation of MnSOD is an important source of $\mathrm{ONOO}^{-}$in this setting. Mitochondria are key sites of cellular death and constitute a primary locus for the intracellular forma- tion and reactions of $\mathrm{ONOO}^{-}$(16). $\mathrm{ONOO}^{-}$-mediated inactivation of mitochondrial MnSOD increases steady-state concentrations of $\mathrm{O}_{2}-$, favoring $\mathrm{ONOO}^{-}$formation, resulting in positive feedback processes that promote mitochondrial dysfunction and the triggering of apoptotic signaling of cell death (16). Therefore, posttranslational nitration of MnSOD may contribute to the induction of spinal cord neuronal and/or glial apoptosis that accompanies opiate-induced tolerance $(7,32)$. The finding that the development of morphineinduced antinociceptive tolerance was not associated with nitration (Figure 3D) or enzymatic inactivation (Figure 3E) of the cytosolic isoform of SOD, namely CuZnSOD, is consistent with previous studies that have shown that the interaction of CuZnSOD with ONOOdoes not affect the catalytic activity of the protein (50). As revealed for what we believe to be the first time in the present study, 2 additional mechanisms through which $\mathrm{ONOO}^{-}-$mediated posttranslational nitration contribute to tolerance are nitration of proteins known to regulate glutamate homeostasis, including the GT GLT-1, and GS (23-25). Why is this important? Several groups have demonstrated in animal models (e.g., of amyotrophic lateral sclerosis and septic shock) that $\mathrm{ONOO}^{-}$can nitrate and inactivate GTs and GS (on Tyr160) (23-25, 51). Nitration of GLT-1 by ONOO- inhibits its ability to transport glutamate from the synaptic cleft to the glial cells, favoring increased synaptic increases in the levels of glutamate and hence excitotoxicity (24), whereas inactivation of the enzymatic activity of GS leads to neurotoxicity $(30,52)$. Furthermore, through feedback regulation, a decrease in the activity of GS can reduce the activity of GTs (52). It is therefore conceivable that if posttranslational nitration of these proteins occurs in response to repeated injection of morphine, this pathway may contribute to the development of tolerance by favoring excitotoxic and neurotoxic glutamate to accumulate within glial cells/neurons and the synaptic cleft, leading to neurotoxicity that accompanies tolerance $(31,32,53)$. Indeed, and as shown in Figure 4, the development of morphine-induced antinociceptive tolerance was associated with significant nitration of both GLT-1 and GS, findings further emphasizing the importance of protein nitration in tolerance. Recently Zanelli and coworkers demonstrated that $\mathrm{ONOO}^{-}$nitrates tyrosine residues on NMDA receptor subunits, an event associated with constant potentiation of synaptic currents, calcium influx, and ultimately increased NMDAR excitability and neuronal excitotoxicity $(54,55)$. Although the relevance of nitration of NMDA receptors in the context of opiate tolerance is not known, it is important to consider its potential involvement, since overactivation of these receptors is linked to morphine-induced tolerance (56). To this end, experiments are underway by our group to understand the contribution of posttranslational nitration of NMDA receptors in opiate tolerance. In this context we acknowledge that 


\section{Table 1}

Posttranslational nitration of MnSOD, GLT-1, and GS during the development of morphine antinociceptive tolerance

\begin{tabular}{|c|c|c|c|c|}
\hline & Treatment group & Nitrated protein & Total lysate & $\beta$-Actin \\
\hline \multicolumn{5}{|l|}{ MnSOD } \\
\hline & Naive & $267.3 \pm 45.6$ & $1,801.4 \pm 3.5$ & $1,752.3 \pm 34.1$ \\
\hline & Vehicle & $398.7 \pm 32.2$ & $1,889.3 \pm 88.6$ & $1,765.3 \pm 73.2$ \\
\hline & Morphine & $1,653 \pm 143.4^{A}$ & $1,963 \pm 75.4$ & $1,789.3 \pm 75.4$ \\
\hline & Morphine + L-NAME (10 mg/kg) & $378.4 \pm 28.6^{B}$ & $1,973.7 \pm 67.2$ & $1,834.3 \pm 73.1$ \\
\hline & Morphine + MnTBAP $3-(10$ mg/kg) & $403.1 \pm 78.3^{B}$ & $1,982.1 \pm 56.2$ & $1,867 \pm 53.7$ \\
\hline & Morphine + FeTM-4-PyP5+ (30 mg/kg) & $396.2 \pm 95.4^{B}$ & $1,945.8 \pm 45.9$ & $1,854 \pm 62.7$ \\
\hline \multicolumn{5}{|c|}{ CuZnSOD } \\
\hline & Naive & 0 & $1,667.1 \pm 16.4$ & $1,654 \pm 34.2$ \\
\hline & Vehicle & 0 & $1,698.4 \pm 45.7$ & $1,678.9 \pm 23.6$ \\
\hline & Morphine & 0 & $1,672.3 \pm 37.4$ & $1,705.3 \pm 37.9$ \\
\hline & Morphine + L-NAME (10 mg/kg) & 0 & $1,669.1 \pm 56.7$ & $1,653.2 \pm 25.9$ \\
\hline & Morphine + MnTBAP3- $(10$ mg/kg) & 0 & $1,661.9 \pm 29.3$ & $1,675 \pm 43.7$ \\
\hline & Morphine + FeTM-4-PyP5+ (30 mg/kg) & 0 & $1,692 \pm 45.4$ & $1,710.2 \pm 56.2$ \\
\hline \multicolumn{5}{|c|}{ 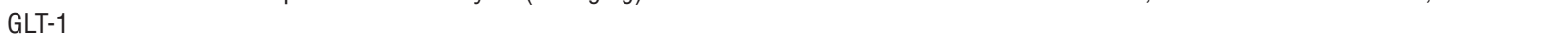 } \\
\hline & Naive & $609.2 \pm 45.7$ & $1,934.5 \pm 56.2$ & $1,201 \pm 34.3$ \\
\hline & Vehicle & $678.3 \pm 36.3$ & $1,989.3 \pm 35.7$ & $1,267.8 \pm 23.6$ \\
\hline & Morphine & $1,602.1 \pm 34.7^{A}$ & $1,894.5 \pm 45.1$ & $1,204.5 \pm 78.2$ \\
\hline & Morphine + L-NAME (10 mg/kg) & $698.6 \pm 89.2^{B}$ & $1,843.1 \pm 67.2$ & $1,215.4 \pm 54.3$ \\
\hline & Morphine + MnTBAP3- $(10$ mg/kg) & $745.2 \pm 67.1^{\mathrm{B}}$ & $1,904.2 \pm 55.7$ & $1,254.8 \pm 87.1$ \\
\hline & Morphine + FeTM-4-PyP5+ $(30 \mathrm{mg} / \mathrm{kg})$ & $703.37 \pm 95.4^{B}$ & $1,891.4 \pm 68.3$ & $1,237.9 \pm 68.3$ \\
\hline \multicolumn{5}{|c|}{ 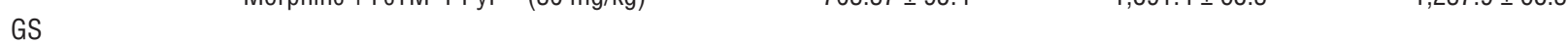 } \\
\hline & Naive & $207.1 \pm 14.7$ & $1,654.2 \pm 42.1$ & $1,519.2 \pm 45.1$ \\
\hline & Vehicle & $224.6 \pm 23.2$ & $1,623.1 \pm 32.4$ & $1,567.7 \pm 44.9$ \\
\hline & Morphine & $921.4 \pm 15.7^{A}$ & $1,612.8 \pm 21.3$ & $1,534.6 \pm 77.8$ \\
\hline & Morphine + L-NAME (10 mg/kg) & $198.7 \pm 35.2^{\mathrm{B}}$ & $1,615.4 \pm 56.3$ & $1590.3 \pm 64.5$ \\
\hline & Morphine + MnTBAP $3-(10$ mg/kg) & $212.4 \pm 20.4^{B}$ & $1,599.2 \pm 18.5$ & $1,546.5 \pm 89.4$ \\
\hline & Morphine + FeTM-4-PyP5+ (30 mg/kg) & $195.7 \pm 24.1^{B}$ & $1,634 \pm 58.7$ & $1,562.9 \pm 73.5$ \\
\hline
\end{tabular}

Repeated administration of morphine led to nitration of MnSOD, GLT-1, and GS but not of CuZnSOD as measured by immunoprecipitation. Total levels of these proteins did not change with the various treatments as measured by Western blot analysis. All results are expressed as densitometry units (mean \pm SEM) for 6 gel results obtained from different animals. ${ }^{A} P<0.001$ for morphine alone versus vehicle; ${ }^{B} P<0.01$ for morphine plus drug versus morphine alone.

morphine-induced antinociceptive tolerance may involve altered nociceptive signaling at several levels of the neuroaxis; characterization of events in other central nervous system tissues is an exciting avenue for future studies.

Chronic administration of morphine promotes neuroimmune activation as evidenced by activation of spinal cord glial cells, production of proinflammatory cytokines such as TNF- $\alpha$, IL- $1 \beta$, and IL-6, and spinal sensitization (8-10). Thus inhibitors of glial cell metabolism and/or anticytokine approaches block morphineinduced antinociceptive tolerance and hyperalgesia (8-10). The possible mechanisms for chronic morphine-induced glial cell activation are not known with certainty. $\mu$-Opiate receptors are present on microglia and astrocytes (57), but acute administration of morphine does not activate these cells (10). On the other hand, morphine primes glial cells for enhanced production of proinflammatory cytokines (58). Our results suggest that $\mathrm{ONOO}^{-}$is a signaling molecule involved in the increased formation of TNF- $\alpha$, IL- $1 \beta$, and IL-6. As reported by our group and others, a mechanism by which $\mathrm{ONOO}^{-}$leads to the generation of such proinflammatory cytokines is through activation of redox-sensitive transcription factors such as NF- $\mathrm{KB}$ and AP-1 as well as activation of MAPK kinases such as p38 kinase (59-61). These results suggest that attenuation of morphine tolerance by $\mathrm{ONOO}^{-}$decomposition catalysts such as FeTM-4-PyP ${ }^{5+}$ may be secondary to the suppression of repeated morphine-induced spinal neuroimmune activation promoted by $\mathrm{ONOO}^{-}$.
It has become increasingly recognized that under severe oxidative and nitrosative stress situations, excessive DNA damage causes overactivation of the nuclear enzyme PARP, a critical intracellular mechanism of neurotoxicity and cell death $(11,62,63)$. $\mathrm{ONOO}^{-}$is one of the reactive species that has been considered to be a major oxidant responsible for DNA strand breakage, which then activates the enzyme (11). PARP activation induces excitotoxic transsynaptic morphological changes in superficial dorsal horn "dark neurons" in morphine-induced antinociceptive tolerance and hyperalgesia as well as in neuropathic pain $(64,65)$. As shown in Figure 7 , repeated administration of morphine led to oxidative DNA damage as evidenced by an increase in the levels of 8-OHdG in the spinal cord and increased PARP activity, and these events were blocked by FeTM-4$\mathrm{PyP}^{5+}$ (or L-NAME and MnTBAP ${ }^{3-}$ ). Our results support the work by Mayer and colleagues as they confirm activation of PARP (64) and extend these earlier observations by establishing a role of $\mathrm{ONOO}^{-}$in PARP activation during antinociceptive tolerance to morphine.

The mechanisms leading to $\mathrm{ONOO}^{-}$formation are not known although several possibilities exist, including $\mu$ and NMDA receptor activation as well as activation of glial cells and cytokine formation, as these are associated with the synthesis and production of its precursors, namely $\mathrm{NO}$ and $\mathrm{ONOO}^{-}(13,66-71)$.

In summary, our results have established a key role for $\mathrm{ONOO}^{-}$in the development of morphine-induced tolerance, providing what is, to our knowledge, a novel mechanistic rationale for development 


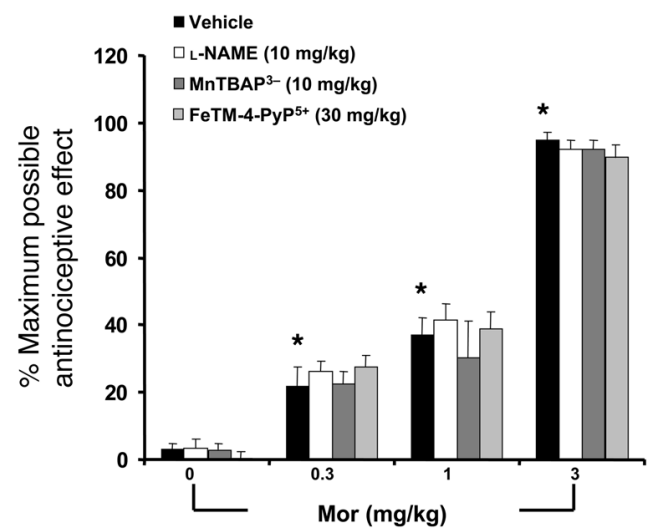

of $\mathrm{ONOO}^{-}$-targeted approaches to alleviate the burden of suffering from chronic severe pain by restoring the sensitivity and therapeutic efficacy of opiates. The broader implications of our findings on the importance of protein tyrosine nitration in this setting further suggest that a comprehensive approach to understanding the functional relevance of posttranslational tyrosine nitration and modification may identify additional non-opiate pharmacological strategies for multimodality therapy of chronic pain. Considering the appreciable molecular, biochemical, and pharmacological similarities between opiate-mediated hypersensitivity, and hypersensitivity associated with chronic neuropathic pain from diabetes mellitus and other sensory neuropathies $(2,8,72), \mathrm{ONOO}^{-}$may be a viable therapeutic target in both conditions.

\section{Methods}

Induction of morphine-induced antinociceptive tolerance in mice

Male CD-1 mice (24-30 g; Charles River Laboratory) were housed and cared for in accordance with the guidelines of the Institutional Animal Care and Use Committee (IACUC) of the Saint Louis University Health Science Center

\section{Figure 5}

On day 5 acute injection of different doses of morphine $(0.3-3 \mathrm{mg} / \mathrm{kg})$ in animals that received saline over 4 days produced a significant dosedependent antinociceptive response when compared with responses obtained in naive group. The antinociceptive response to morphine was not altered in animals that were treated over 4 days with L-NAME $(10 \mathrm{mg} / \mathrm{kg} / \mathrm{d})$, MnTBAP $^{3-}(10 \mathrm{mg} / \mathrm{kg} / \mathrm{d})$, or FeTM-4-PyP ${ }^{5+}(30 \mathrm{mg} / \mathrm{kg} / \mathrm{d})$, indicating lack of acute interaction between morphine and L-NAME, $\mathrm{MnTBAP}^{3-}$, or FeTM-4-PyP ${ }^{5+}$. Results are expressed as mean \pm SEM for 10 animals. ${ }^{*} P<0.001$ for the vehicle group when compared to values obtained in the absence of morphine.

and in accordance with the NIH Guidelines on Laboratory Animal Welfare and the University of Catanzaro "Magna Graecia" in compliance with Italian regulations on protection of animals used for experimental and other scientific purposes (D.M. 116192) as well as with European Economic Community regulations. The IACUC of Saint Louis University Health Science Center and the University of Catanzaro "Magna Graecia" approved all studies. Mice were housed 5-7 per cage and maintained under identical conditions of temperature $\left(21 \pm 1^{\circ} \mathrm{C}\right)$ and humidity $(60 \% \pm 5 \%)$ with a 12 -hour light/12-hour dark cycle and allowed food ad libitum. Nociceptive thresholds were determined by measuring latencies (in seconds) of mice placed in a transparent glass cylinder on a hot plate (Ugo Basile) maintained at $52^{\circ} \mathrm{C}$. Determination of antinociception was assessed between 7:00 am and 10:00 am. All injections were given i.p. or s.c. in a $0.1-\mathrm{ml}$ volume at approximately 7 am and $4 \mathrm{pm}$. Drugs or saline were given before each dose on morphine. Responses indicative of nociception included intermittent lifting and/or licking of the hindpaws or escape behavior. Hot plate latencies were taken in mice from all groups on day 5 before (baseline latency) and 40 minutes after an acute dose of morphine $(0.3-3 \mathrm{mg} / \mathrm{kg}$ ) or its vehicle (saline) (response latency). Baseline values from all groups as measured on day 5 before injection of the acute dose of morphine or saline were statistically insignificant and ranged between 6 and 8 seconds. Results are expressed as percentage of maximum possible antinociceptive effect, which was calculated as follows: (response latency - baseline latency) / (cut-off latency - baseline latency) $\times 100$. A cut-off latency of 20 seconds was employed to prevent tissue damage. Six to twelve mice per group were used,
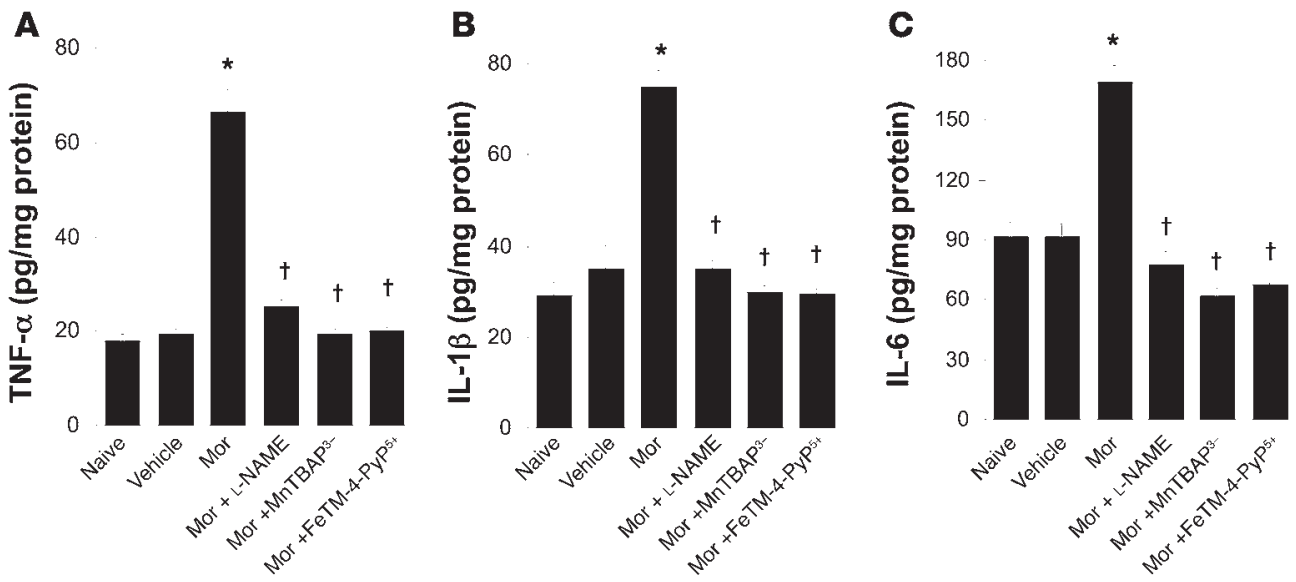

Figure 6

Acute injection of morphine $(3 \mathrm{mg} / \mathrm{kg})$ on day 5 in animals that received saline over 4 days (vehicle group) did not increase dorsal horn tissue levels of TNF- $\alpha$ (A), IL-1 $\beta$ (B), or IL-6 (C) when compared with animals that received an equivalent volume of its vehicle (naive group). On the other hand, acute administration of morphine in animals that received repeated administration of morphine (morphine group) led to a significant increase in TNF- $\alpha$, IL-1 $\beta$, and IL- 6 in dorsal horn tissues. This increase was attenuated by coadministration of morphine over 4 days with L-NAME $(10 \mathrm{mg} / \mathrm{kg} / \mathrm{d})$, MnTBAP ${ }^{-}$(10 mg/kg/d), or FeTM-4-PyP5+ $(30 \mathrm{mg} / \mathrm{kg} / \mathrm{d})$. Results are expressed as mean \pm SEM for 12 animals. ${ }^{*} P<0.001$ for morphine alone versus vehicle; ${ }^{\dagger} P<0.001$ for morphine plus drug versus morphine alone. 


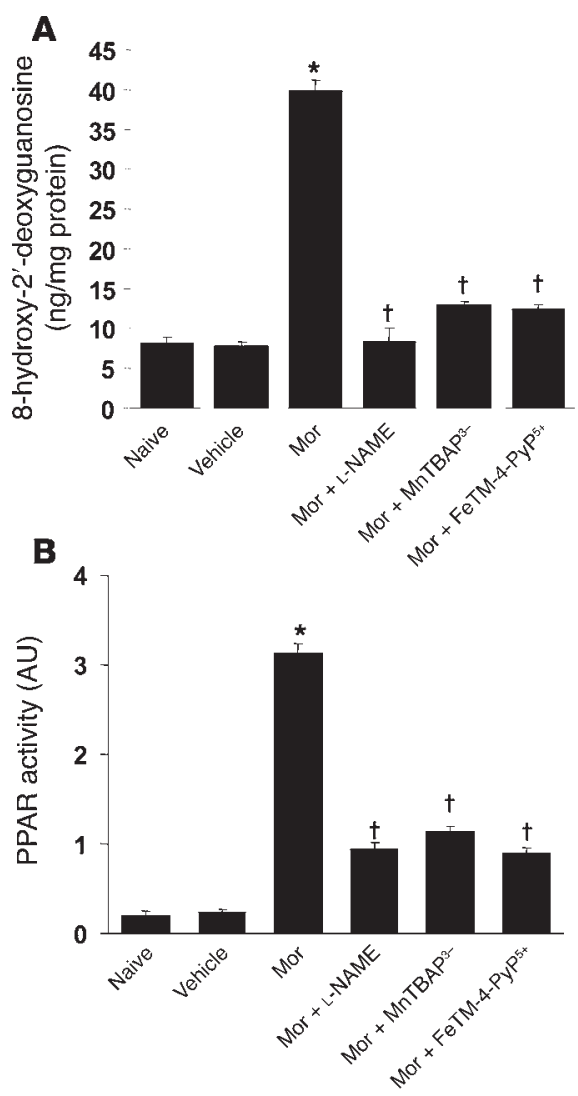

and all experiments were conducted with the experimenters blinded to treatment conditions. Unless specified, all drugs were purchased from SigmaAldrich. Charges on MnTBAP ${ }^{3-}$ and FeTM-4-PyP ${ }^{5+}$ were omitted for clarity on all Figures. The following experimental groups were used.

Naive group. In this group, mice were injected twice a day with an i.p. injection of saline (vehicle used to deliver the drugs to the other groups over 4 days) and a s.c. injection of saline (vehicle used to deliver morphine to the other groups over 4 days). On day 5 mice received an i.p. injection of saline followed 15 minutes later by a s.c. injection of saline.

Naive plus drug groups. In these groups, mice were injected twice a day for 4 days with an i.p. injection of the highest dose of L-NAME $(10 \mathrm{mg} / \mathrm{kg} / \mathrm{d})$, MnTBAP $^{3}\left(10 \mathrm{mg} / \mathrm{kg} / \mathrm{d}\right.$; Calbiochem), or FeTM-4-PyP ${ }^{5+}(30 \mathrm{mg} / \mathrm{kg} / \mathrm{d}$; Calbiochem) and a s.c. injection of saline. On day 5 mice received an i.p. injection of L-NAME $(5 \mathrm{mg} / \mathrm{kg}), \mathrm{MnTBAP}^{3}(5 \mathrm{mg} / \mathrm{kg})$, or FeTM-4-PyP ${ }^{5+}$ $(15 \mathrm{mg} / \mathrm{kg})$ followed 15 minutes later by a s.c. injection of saline.

Vehicle group. In this group, mice were injected twice a day for 4 days with an i.p. injection of saline and a s.c. injection of saline. On day 5 mice received an i.p. injection of saline followed 15 minutes later by a s.c. injection of

\section{Figure 8}

Illustration summarizing the key findings of this study depicting the role(s) of ONOO- in the development of morphine-induced antinociceptive tolerance. Formation of ONOO- in the spinal cord during repeated administration of morphine plays a critical role in the development of morphine-induced antinociceptive tolerance through at least 3 biochemical pathways: posttranslational nitration, neuroimmune activation, and release of proinflammatory cytokines, and oxidative DNA damage and PARP activation. Inhibition of its formation by removal of $\mathrm{NO}$ and $\mathrm{O}_{2}^{-}$or by catalytically decomposing it by ONOO- decomposition catalysts such as FeTM-4-PyP5+ blocked these pathways, leading to inhibition of antinociceptive tolerance.

\section{Figure 7}

Acute injection of morphine $(3 \mathrm{mg} / \mathrm{kg})$ on day 5 in animals that received saline over 4 days (vehicle group) did not increase dorsal horn tissue levels of $8-\mathrm{OHdG}$ and did not activate PARP when compared with animals that received an equivalent volume of its vehicle (naive group). On the other hand, acute administration of morphine on day 5 after repeated administration of morphine (morphine group) led to significant increase in dorsal horn tissue levels of $8-\mathrm{OHdG}(\mathbf{A})$ and substantially activated PARP (B). These biochemical changes were significantly attenuated by coadministration of morphine over 4 days with L-NAME $(10 \mathrm{mg} / \mathrm{kg} / \mathrm{d})$, MnTBAP3- $(10 \mathrm{mg} / \mathrm{kg} / \mathrm{d})$, or FeTM-4-PyP5+ $(30 \mathrm{mg} / \mathrm{kg} / \mathrm{d})$. When compared with the naive groups, the acute dose of morphine did not increase levels of these cytokines. Results are expressed as mean \pm SEM for 12 animals. ${ }^{*} P<0.001$ for morphine alone versus vehicle; ${ }^{\dagger} P<0.001$ for morphine plus drug versus morphine alone.

acute morphine, eliciting near-maximum antinociception $(3 \mathrm{mg} / \mathrm{kg})$. A direct interaction with acute morphine over a broad range of doses, the effects of L-NAME, $\mathrm{MnTBAP}^{3}$, and $\mathrm{FeTM}-4-\mathrm{PyP}^{5+}$ were also tested against acute doses of morphine, eliciting between $10 \%$ and $40 \%$ antinociceptive responses within 40 minutes of administration ( 0.3 and $1 \mathrm{mg} / \mathrm{kg}$, s.c.).

Vehicle plus drug groups. In these groups, mice were injected twice a day for 4 days with an i.p. injection of the highest dose of L-NAME $(10 \mathrm{mg} / \mathrm{kg} / \mathrm{d})$, $\operatorname{MnTBAP}^{3}(10 \mathrm{mg} / \mathrm{kg} / \mathrm{d})$, or FeTM-4-PyP ${ }^{5+}(30 \mathrm{mg} / \mathrm{kg} / \mathrm{d})$ and a s.c. injection of saline. On day 5 mice received an i.p. injection of L-NAME $(5 \mathrm{mg} / \mathrm{kg})$, $\mathrm{MnTBAP}^{3}(5 \mathrm{mg} / \mathrm{kg})$, or FeTM-4-PyP ${ }^{5+}(15 \mathrm{mg} / \mathrm{kg})$, followed 15 minutes later by s.c. doses of acute morphine giving between $10 \%$ and $95 \%$ maximum antinociceptive responses within 40 minutes of administration $(0.1-3 \mathrm{mg} / \mathrm{kg})$.

Morphine group. In this group, mice were injected twice a day for 4 days with an i.p. injection of saline and a s.c. injection of morphine $(20 \mathrm{mg} / \mathrm{kg} / \mathrm{d})$. On day 5 mice received an i.p. injection of saline followed 15 minutes later by a s.c. dose of acute morphine $(3 \mathrm{mg} / \mathrm{kg})$.

Morphine plus drug groups. In this group, mice were injected twice a day for 4 days with an i.p. injection of varying doses of L-NAME $(1,3$, and $10 \mathrm{mg} / \mathrm{kg} / \mathrm{d}), \mathrm{MnTBAP}^{3-}$ (1, 3, and $10 \mathrm{mg} / \mathrm{kg} / \mathrm{d}$ ), or FeTM-4-PyP ${ }^{5+}$ (3, 10, and $30 \mathrm{mg} / \mathrm{kg} / \mathrm{d})$, followed by s.c. injection of morphine $(20 \mathrm{mg} / \mathrm{kg} / \mathrm{d})$. On day 5 mice received an i.p. dose of L-NAME $(5 \mathrm{mg} / \mathrm{kg}), \operatorname{MnTBAP}^{3}(5 \mathrm{mg} / \mathrm{kg})$, and FeTM-4-PyP $\mathrm{P}^{5+}(15 \mathrm{mg} / \mathrm{kg})$, followed 15 minutes later by the s.c. dose of acute morphine $(3 \mathrm{mg} / \mathrm{kg})$.

In another set of experiments, and in order to address whether L-NAME, $\mathrm{MnTBAP}^{3-}$, or FeTM-4-PyP ${ }^{5+}$ reverse the expression of tolerance, mice were treated twice a day with morphine as described above and on day 5 received a single i.p. dose of L-NAME $(10 \mathrm{mg} / \mathrm{kg}), \mathrm{MnTBAP}^{3-}(10 \mathrm{mg} / \mathrm{kg})$, or FeTM$4-\mathrm{PyP}^{5+}(30 \mathrm{mg} / \mathrm{kg})$ followed 15 minutes later by the acute dose of morphine $(3 \mathrm{mg} / \mathrm{kg})$.

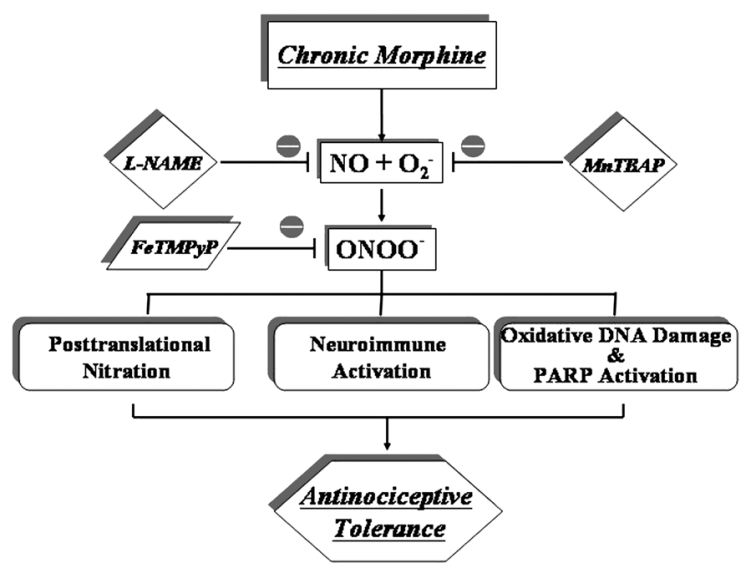


On day 5 and after the behavioral tests, spinal cord tissues from the lumbar enlargement segment of the spinal cord (L4-L6) and dorsal horn tissues were removed and tissues processed for immunohistochemical, Western blot, and biochemical analysis.

\section{Immunobistochemical detection of nitrated proteins}

Animals were anesthetized with pentobarbital and transcardially perfused with normal saline followed by $4 \%$ paraformaldehyde solution. Dorsal half of the spinal cord lumbar region enlargement (L4-L6) was processed for immunostaining as previously described (15). Monoclonal anti-nitrotyrosine antibody (1:100 in 10\% normal horse serum; Calbiochem) was used as primary antibody and the samples processed for immunolabeling visualization by incubation with correspondent secondary antibody, $\mathrm{A} / \mathrm{B}$ complex, and diaminobenzidine according to the manufacturer's instructions (Vector ABC Elite Kit; Vector Laboratories). For immunoreaction specificity, some sections were incubated with either primary antibody or secondary antibody alone.

Immunoprecipitation and Western blot analyses. Dorsal half of the spinal cord lumbar region enlargement (L4-L6) were obtained as described previously $(14,15,73)$. The resulting lysates samples were stored immediately at $-80^{\circ} \mathrm{C}$ and immunoprecipitation of tyrosine nitrated protein followed by Western blot analysis performed as previously described $(14,15)$. For immunoprecipitation of nitrated proteins, a well-characterized affinity-purified anti-nitrotyrosine monoclonal antibody conjugated to agarose beads from Upstate Biotechnology was used according to the manufacturer's instructions. To determine whether MnSOD, CuZnSOD, GLT-1, and GS were nitrated, Western blot analysis of i.p. protein complex and total lysates were performed using antibodies specific to these proteins. Briefly, the immunoprecipitated proteins were resolved in $12 \%$ SDS-PAGE mini and proteins transferred to nitrocellulose membranes. Membranes were blocked for 1 hour at room temperature in $1 \% \mathrm{BSA} / 0.1 \%$ thimerosal in $50 \mathrm{mM}$ Tris- $\mathrm{HCl}$ (pH 7.4)/150 mM NaCl/0.01\% Tween-20 (TBS/T), followed by incubation with rabbit polyclonal antibodies for MnSOD and CuZnSOD (1:2000; Upstate Biotechnology), GLT-1 (1:1000; Alpha Diagnostic International), and monoclonal antibody for GS (1:4000; Transduction Laboratories). Membranes were then washed with TBS/T and incubated secondary antibodies conjugated to horseradish peroxidase for 1 hour at room temperature. After washes, proteins were visualized by enhanced chemiluminescence (ECL or Femto kit; Amernaive Biosciences or Pierce Biotechnology, respectively). Rat brain lysate from Upstate Biotechnology that contained most of the proteins expressed by nervous tissue was used as positive control and for equal loading of membranes, and total lysates blots were stripped and reprobed with a monoclonal antibody specific for $\beta$-actin at a dilution of 1:2000. Quantitation of protein bands of interest was determined by densitometry using ImageQuant 5.2 software (Molecular Dynamics).

1. Renfrey, S., Downton, C., and Featherstone, J. 2003. The painful reality. Nat. Rev. Drug Discov. 2:175-176.

2. Mao, J., Price, D.D., and Mayer, D.J. 1995. Mechanisms of hyperalgesia and morphine tolerance: a current view of their possible interactions. Pain. 62:259-274.

3. Arner, S., Rawal, N., and Gustafsson, L.L. 1988. Clinical experience of long-term treatment with epidural and intrathecal opioids--a nationwide survey. Acta Anaesthesiol. Scand. 32:253-259.

4. Ossipov, M.H., et al. 2004. Antinociceptive and nociceptive actions of opioids. J. Neurobiol. 61:126-148.

5. Foley, K.M. 1995. Misconceptions and controversies regarding the use of opioids in cancer pain. Anticancer Drugs. 6(Suppl. 3):4-13.

6. Mao, J., Sung, B., Ji, R.R., and Lim, G. 2002. Neuronal apoptosis associated with morphine tolerance: evidence for an opioid-induced neurotoxic mechanism. J. Neurosci. 22:7650-7661.

7. Mao, J., and Mayer, D.J. 2001. Spinal cord neuro-

\section{Measurement of MnSOD and CuZnSOD activities}

Dorsal half of the spinal cord lumbar region enlargement (L4-L6) were homogenized with $10 \mathrm{mM}$ PBS ( $\mathrm{pH}$ 7.4) in a Polytron homogenizer and then sonicated on ice for 1 minute ( 3 times, 20 seconds each time). The sonicated samples were subsequently centrifuged at $1,100 \mathrm{~g}$ for 10 minutes and SOD activity was measured in the supernatants. In brief, a competitive inhibition assay was performed that used xanthine-xanthine oxidase-generated $\mathrm{O}_{2}{ }^{-}$to reduce nitroblue tetrazolium (NBT) to blue tetrazolium salt. The reaction was performed in sodium carbonate buffer $(50 \mathrm{mM}, \mathrm{pH} 10.1)$ containing EDTA $(0.1 \mathrm{mM})$, nitroblue tetrazolium $(25 \mu \mathrm{M})$, and xanthine and xanthine oxidase $(0.1 \mathrm{mM}$ and $2 \mathrm{nM}$, respectively; Boehringer). The rate of NBT reduction was monitored spectrophotometrically (PerkinElmer Lambda 5 Spectrophotometer) at $560 \mathrm{~nm}$. The amount of protein required to inhibit the rate of NTB reduction by $50 \%$ was defined as 1 unit of enzyme activity. CuZnSOD activity was inhibited by performing the assay in the presence of $2 \mathrm{mM} \mathrm{NaCN}$ after preincubation for 30 minutes. Enzymatic activity was expressed in units per milligram of protein (15).

Statistics. For paired group analysis, Students $t$ test was performed. For paired multiple group analysis, ANOVA followed by Student-Newman-Keuls test was employed to analyze the data. Results are expressed as mean \pm SEM. A statistically significant difference was defined as a $P$ value of less than 0.05 .

\section{Acknowledgments}

We would like to thank Harry Ischiropoulos (University of Pennsylvania, Philadelphia, Pennsylvania, USA) and Mark R. Payne (University of Indiana School of Medicine, Indianapolis, Indiana, USA) for their invaluable input. Technical support was kindly provided by Giovanni Politi (University of Catanzaro, Catanzaro, Italy). This work was supported by grants from COFIN 2005 (2005057404004, to V. Mollace), Saint Louis University Seed Fund (to D. Salvemini), and IRCCS Centro Neurolesi "Bonino-Pulejo" grant (to S. Cuzzocrea) and by funds from the University of Florence.

Received for publication April 17, 2007, and accepted in revised form August 1, 2007.

Address correspondence to: Daniela Salvemini, Department of Internal Medicine, Division of Pulmonary, Critical Care and Sleep Medicine, Saint Louis University School of Medicine, St. Louis 63104, USA. Phone: (314) 577-8856; Fax: (314) 577-8859; E-mail: salvemd@slu.edu.

Carolina Muscoli and Salvatore Cuzzocrea contributed equally to this work.

plasticity following repeated opioid exposure and its relation to pathological pain. Ann. N. Y. Acad. Sci. 933:175-184.

8. Watkins, L.R., Hutchinson, M.R., Johnston, I.N., and Maier, S.F. 2005. Glia: novel counter-regulators of opioid analgesia. Trends Neurosci. 28:661-669.

9. Watkins, L.R., et al. 2007. Norman Cousins Lecture. Glia as the "bad guys": implications for improving clinical pain control and the clinical utility of opioids. Brain Behav. Immun. 21:131-146.

10. Song, P., and Zhao, Z.Q. 2001. The involvement of glial cells in the development of morphine tolerance. Neurosci. Res. 39:281-286.

11. Jagtap, P., and Szabo, C. 2005. Poly(ADP-ribose) polymerase and the therapeutic effects of its inhibitors. Nat. Rev. Drug Discov. 4:421-440.

12. Beckman, J.S., Beckman, T.W., Chen, J., Marshall, P.A., and Freeman, B.A. 1990. Apparent hydroxyl radical production by peroxynitrite: implications for endothelial injury from nitric oxide and superoxide.
Proc. Natl. Acad. Sci. U. S. A. 87:1620-1624.

13. Salvemini, D., Jensen, M.P., Riley, D.P., and Misko, T.P. 1998. Therapeutic manipulations of peroxynitrite. Drug News Perspect. 11:204-214.

14. Muscoli, C., et al. 2004. Superoxide-mediated nitration of spinal manganese superoxide dismutase: a novel pathway in N-methyl-D-aspartate-mediated hyperalgesia. Pain. 111:96-103.

15. Wang, Z.Q., et al. 2004. A newly identified role for superoxide in inflammatory pain. J. Pharmacol. Exp. Ther. 309:869-878.

16. Radi, R. 2004. Nitric oxide, oxidants, and protein tyrosine nitration. Proc. Natl. Acad. Sci. U. S. A. 101:4003-4008.

17. McCord, J.M., and Fridovich, I. 1969. Superoxide dismutase. An enzymic function for erythrocuprein (hemocuprein). J. Biol. Chem. 244:6049-6055.

18. Macmillan-Crow, L.A., and Cruthirds, D.L. 2001. Invited review: manganese superoxide dismutase in disease. Free Radic. Res. 34:325-336. 
19. MacMillan-Crow, L.A., Cruthirds, D.L., Ahki, K.M. Sanders, P.W., and Thompson, J.A. 2001. Mitochondrial tyrosine nitration precedes chronic allograft nephropathy. Free Radic. Biol. Med. 31:1603-1608.

20. MacMillan-Crow, L.A., and Thompson, J.A. 1999. Tyrosine modifications and inactivation of active site manganese superoxide dismutase mutant (Y34F) by peroxynitrite. Arch. Biochem. Biophys. 366:82-88.

21. Yamakura, F., et al. 2001. Modification of a single tryptophan residue in human $\mathrm{Cu}, \mathrm{Zn}$-superoxide dismutase by peroxynitrite in the presence of bicarbonate. Biochim. Biophys. Acta. 1548:38-46.

22. Yamakura, F., Taka, H., Fujimura, T., and Murayama, K. 1998. Inactivation of human manganesesuperoxide dismutase by peroxynitrite is caused by exclusive nitration of tyrosine 34 to 3-nitrotyrosine. J. Biol. Chem. 273:14085-14089.

23. Trotti, D., Rolfs, A., Danbolt, N.C., Brown, R.H., Jr., and Hediger, M.A. 1999. SOD1 mutants linked to amyotrophic lateral sclerosis selectively inactivate a glial glutamate transporter. Nat. Neurosci. 2:848.

24. Trotti, D., et al. 1996. Peroxynitrite inhibits glutamate transporter subtypes. J. Biol. Chem. 271:5976-5979.

25. Gorg, B., Wettstein, M., Metzger, S., Schliess, F., and Haussinger, D. 2005. Lipopolysaccharideinduced tyrosine nitration and inactivation of hepatic glutamine synthetase in the rat. Hepatology. 41:1065-1073.

26. Trujillo, K.A., and Akil, H. 1991. Inhibition of morphine tolerance and dependence by the NMDA receptor antagonist MK-801. Science. 251:85-87.

27. Danbolt, N.C. 2001. Glutamate uptake. Prog. Neurobiol. 65:1-105.

28. Mennerick, S., et al. 1999. Substrate turnover by transporters curtails synaptic glutamate transients. J. Neurosci. 19:9242-9251.

29. Lievens, J.C., Bernal, F., Forni, C., Mahy, N., and Kerkerian-Le Goff, L. 2000. Characterization of striatal lesions produced by glutamate uptake alteration: cell death, reactive gliosis, and changes in GLT1 and GADD45 mRNA expression. Glia. 29:222-232.

30. Muscoli, C., et al. 2005. The effect of inflammatory stimuli on NMDA-related activation of glutamine synthase in human cultured astroglial cells. Neurosci. Lett. 373:184-188.

31. Nakagawa, T., et al. 2001. Inhibition of morphine tolerance and dependence by MS-153, a glutamate transporter activator. Eur. J. Pharmacol. 419:39-45.

32. Mao, J., Sung, B., Ji, R.R., and Lim, G. 2002. Chronic morphine induces downregulation of spinal glutamate transporters: implications in morphine tolerance and abnormal pain sensitivity. J. Neurosci. 22:8312-8323.

33. Moncada, S., Palmer, R.M., and Higgs, E.A. 1991. Nitric oxide: physiology, pathophysiology, and pharmacology. Pharmacol. Rev. 43:109-142.

34. Faulkner, K.M., Liochev, S.I., and Fridovich, I. 1994. Stable Mn(III) porphyrins mimic superoxide dismutase in vitro and substitute for it in vivo. J. Biol. Chem. 269:23471-23476.

35. Muscoli, C., et al. 2003. On the selectivity of superoxide dismutase mimetics and its importance in pharmacological studies. Br. J. Pharmacol. 140:445-460.

36. Lodovici, M., Casalini, C., Cariaggi, R., Michelucci, L., and Dolara, P. 2000. Levels of 8-hydroxydeoxyguanosine as a marker of DNA damage in human leukocytes. Free Radic. Biol. Med. 28:13-17.

37. Salvemini, D., Wang, Z.Q., Stern, M.K., Currie,
M.G., and Misko, T.P. 1998. Peroxynitrite decomposition catalysts: therapeutics for peroxynitritemediated pathology. Proc. Natl. Acad. Sci. U. S. A. 95:2659-2663.

38. Salvemini, D., et al. 1996. Nitric oxide: a key mediator in the early and late phase of carrageenaninduced rat paw inflammation. Br.J. Pharmacol. 118:829-838.

39. Salvemini, D., et al. 1996. Evidence of peroxynitrite involvement in the carrageenan-induced rat paw edema. Eur. J. Pharmacol. 303:217-220.

40. Ossipov, M.H., Lai, J., Vanderah, T.W., and Porreca, F. 2003. Induction of pain facilitation by sustained opioid exposure: relationship to opioid antinociceptive tolerance. Life Sci. 73:783-800.

41. Vanderah, T.W., Ossipov, M.H., Lai, J., Malan, T.P., Jr., and Porreca, F. 2001. Mechanisms of opioid-induced pain and antinociceptive tolerance: descending facilitation and spinal dynorphin. Pain. 92:5-9.

42. Taylor, D.A., and Fleming, W.W. 2001. Unifying perspectives of the mechanisms underlying the development of tolerance and physical dependence to opioids. J. Pharmacol. Exp. Ther. 297:11-18.

43. Simonnet, G., and Rivat, C. 2003. Opioid-induced hyperalgesia: abnormal or normal pain? Neuroreport. 14:1-7.

44. Rothman, R.B. 1992. A review of the role of anti-opioid peptides in morphine tolerance and dependence. Synapse. 12:129-138.

45. Celerier, E., et al. 2000. Long-lasting hyperalgesia induced by fentanyl in rats: preventive effect of ketamine. Anesthesiology. 92:465-472.

46. Celerier, E., Laulin, J.P., Corcuff, J.B., Le Moal, M., and Simonnet, G. 2001. Progressive enhancement of delayed hyperalgesia induced by repeated heroin administration: a sensitization process. J. Neurosci. 21:4074-4080.

47. De Conno, F., et al. 1991. Hyperalgesia and myoclonus with intrathecal infusion of high-dose morphine. Pain. 47:337-339.

48. Devulder, J. 1997. Hyperalgesia induced by highdose intrathecal sufentanil in neuropathic pain. J. Neurosurg. Anesthesiol. 9:146-148.

49. Hess, D.T., Matsumoto, A., Kim, S.O., Marshall, H.E., and Stamler, J.S. 2005. Protein S-nitrosylation: purview and parameters. Nat. Rev. Mol. Cell Biol. 6:150-166

50. Smith, C.D., et al. 1992. Crystal structure of peroxynitrite-modified bovine $\mathrm{Cu}, \mathrm{Zn}$ superoxide dismutase. Arch. Biochem. Biophys. 299:350-355.

51. Minana, M.D., et al. 1997. Modulation of glutamine synthesis in cultured astrocytes by nitric oxide. Cell. Mol. Neurobiol. 17:433-445.

52. Suarez, I., Bodega, G., and Fernandez, B. 2002. Glutamine synthetase in brain: effect of ammonia. Neurochem. Int. 41:123-142.

53. Wen, Z.H., Wu, G.J., Chang, Y.C., Wang, J.J., and Wong, C.S. 2005. Dexamethasone modulates the development of morphine tolerance and expression of glutamate transporters in rats. Neuroscience. 133:807-817.

54. Zanelli, S.A., Ashraf, Q.M., Delivoria-Papadopoulos, M., and Mishra, O.P. 2000. Peroxynitriteinduced modification of the N-methyl-D-aspartate receptor in the cerebral cortex of the guinea pig fetus at term. Neurosci. Lett. 296:5-8.

55. Zanelli, S.A., Ashraf, Q.M., and Mishra, O.P. 2002 Nitration is a mechanism of regulation of the NMDA receptor function during hypoxia. Neuroscience. 112:869-877.
56. Mao, J. 1999. NMDA and opioid receptors: their interactions in antinociception, tolerance and neuroplasticity. Brain Res. Brain Res. Rev. 30:289-304.

57. Peterson, P.K., Molitor, T.W., and Chao, C.C. 1998. The opioid-cytokine connection. J. Neuroimmunol. 83:63-69.

58. Chao, C.C., et al. 1994. Priming effect of morphine on the production of tumor necrosis factor-alpha by microglia: implications in respiratory burst activity and human immunodeficiency virus-1 expression. J. Pharmacol. Exp. Ther. 269:198-203.

59. Gius, D., Botero, A., Shah, S., and Curry, H.A. 1999. Intracellular oxidation/reduction status in the regulation of transcription factors NF-kappaB and AP-1. Toxicol. Lett. 106:93-106.

60. Matata, B.M., and Galinanes, M. 2002. Peroxynitrite is an essential component of cytokines production mechanism in human monocytes through modulation of nuclear factor-kappa B DNA binding activity. J. Biol. Chem. 277:2330-2335.

61. Ndengele, M.M., et al. 2005. Superoxide potentiates NF-kappaB activation and modulates endotoxininduced cytokine production in alveolar macrophages. Shock. 23:186-193.

62. Virag, L. 2005. Structure and function of poly(ADPribose) polymerase-1: role in oxidative stress-related pathologies. Curr. Vasc. Pharmacol. 3:209-214.

63. Schreiber, V., Dantzer, F., Ame, J.C., and de Murcia, G. 2006. Poly(ADP-ribose): novel functions for an old molecule. Nat. Rev. Mol. Cell Biol. 7:517-528.

64. Mayer, D.J., Mao, J., Holt, J., and Price, D.D. 1999. Cellular mechanisms of neuropathic pain, morphine tolerance, and their interactions. Proc. Natl. Acad. Sci. U. S. A. 96:7731-7736.

65. Mao, J., Price, D.D., Zhu, J., Lu, J., and Mayer, D.J. 1997. The inhibition of nitric oxide-activated poly(ADP-ribose) synthetase attenuates transsynaptic alteration of spinal cord dorsal horn neurons and neuropathic pain in the rat. Pain. 72:355-366.

66. Stefano, G.B., et al. 1995. Presence of the mu3 opiate receptor in endothelial cells. Coupling to nitric oxide production and vasodilation. J. Biol. Chem. 270:30290-30293.

67. Lafon-Cazal, M., Pietri, S., Culcasi, M., and Bockaert, J. 1993. NMDA-dependent superoxide production and neurotoxicity. Nature. 364:535-537.

68. Meller, S.T., and Gebhart, G.F. 1993. Nitric oxide (NO) and nociceptive processing in the spinal cord. Pain. 52:127-136.

69. Mollace, V., and Nistico, G. 1995. Release of nitric oxide from astroglial cells: a key mechanism in neuroimmune disorders. Adv. Neuroimmunol. 5:421-430.

70. Li, J., Baud, O., Vartanian, T., Volpe, J.J., and Rosenberg, P.A. 2005. Peroxynitrite generated by inducible nitric oxide synthase and NADPH oxidase mediates microglial toxicity to oligodendrocytes. Proc. Natl. Acad. Sci. U. S. A. 102:9936-9941.

71. Mander, P., and Brown, G.C. 2005. Activation of microglial NADPH oxidase is synergistic with glial iNOS expression in inducing neuronal death: a dual-key mechanism of inflammatory neurodegeneration. J. Neuroinflammation. 2:20.

72. Watkins, L.R., Milligan, E.D., and Maier, S.F. 2001. Glial activation: a driving force for pathological pain. Trends Neurosci. 24:450-455.

73. Takagi, N., Logan, R., Teves, L., Wallace, M.C., and Gurd, J.W. 2000. Altered interaction between PSD95 and the NMDA receptor following transient global ischemia. J. Neurochem. 74:169-178. 